\title{
Matrix metalloproteinase 9 gene polymorphisms are associated with a multiple family history of gastric cancer
}

\author{
Rieko Okada ${ }^{1} \cdot$ Mariko Naito $^{1} \cdot$ Yuta Hattori $^{1} \cdot$ Toshio Seiki $^{1} \cdot$ Kenji Wakai $^{1}$ • \\ Hinako Nanri ${ }^{2} \cdot$ Miki Watanabe $^{3,4} \cdot$ Sadao Suzuki $^{5}$ - Tara Sefanya Kairupan ${ }^{6}$. \\ Naoyuki Takashima ${ }^{7}$ - Haruo Mikami ${ }^{8}$ Keizo Ohnaka ${ }^{9}$ Yoshiyuki Watanabe ${ }^{10}$. $^{\circ}$ \\ Sakurako Katsuura-Kamano ${ }^{11}$ - Michiaki Kubo ${ }^{12} \cdot$ Nobuyuki Hamajima $^{13}$. \\ Hideo Tanaka ${ }^{3,4}$ - The Japan Multi-institutional Collaborative Cohort Study Group
}

Received: 17 December 2015/Accepted: 30 March 2016/Published online: 6 April 2016

(C) The International Gastric Cancer Association and The Japanese Gastric Cancer Association 2016

\begin{abstract}
Background A family history of gastric cancer (GC) is a well-known risk factor of GC. Genetic variations in genes of matrix metalloproteinases (MMPs) and tissue inhibitors of metalloproteinases (TIMPs) have been related to the risk of GC, but their association with familial background is not clear. We investigated whether individuals with a multiple family history of GC have more risk genotypes of MMP/ TIMP genes.

Methods We genotyped ten common functional polymorphisms of MMP/TIMP genes in 4427 individuals aged 35-69 years without a history of GC who were enrolled in the Japan Multi-institutional Collaborative Cohort Study. Individuals who have two or more first-degree relatives (parents and siblings) with GC were categorized as having
\end{abstract}

Rieko Okada

rieokada@med.nagoya-u.ac.jp

1 Department of Preventive Medicine, Nagoya University Graduate School of Medicine, 65 Tsurumai-cho, Showa-ku, Nagoya 4668550, Japan

2 Department of Public Health, Showa University School of Medicine, Tokyo, Japan

3 Division of Epidemiology and Prevention, Aichi Cancer Center Research Institute, Nagoya, Japan

4 Department of Epidemiology, Nagoya University Graduate School of Medicine, Nagoya, Japan

5 Department of Public Health, Nagoya City University Graduate School of Medical Sciences, Nagoya, Japan

6 Department of International Island and Community Medicine, Kagoshima University Graduate School of Medical and Dental Sciences, Kagoshima, Japan

7 Department of Health Science, Shiga University of Medical Science, Otsu, Japan a multiple family history. Odds ratios (ORs) for multiple family history compared with no family history were calculated.

Results MMP9 279QQ (rs17576) was more frequently observed in individuals whose both parents had a history of GC $(n=23)$ and in individuals for whom one parent and their sibling(s) had a history of GC $(n=36)$ compared with those with no family history $(n=3816)[30.4 \%$ vs $11.6 \%$, OR $4.34,95 \%$ confidence interval (CI) $1.45-13.03$ and $16.7 \%$ vs $11.6 \%$, OR $2.26,95 \% \mathrm{CI}$ 0.81-6.27 after adjustment for age, sex, and current smoking]. The population attributable fraction was $38.1 \%$. The haplotype MMP9-1562C/279Q/668Q was more frequently observed in individuals whose both parents had a history of GC and in individuals for whom one parent and
8 Division of Cancer Prevention and Epidemiology, Cancer Prevention Center, Chiba Cancer Center Research Institute, Chiba, Japan

9 Department of Geriatric Medicine, Graduate School of Medical Sciences, Kyushu University, Fukuoka, Japan

10 Department of Epidemiology for Community Health and Medicine, Kyoto Prefectural University of Medicine Graduate School of Medical Science, Kyoto, Japan

11 Department of Preventive Medicine, Institute of Biomedical Sciences, Tokushima University Graduate School, Tokushima, Japan

12 RIKEN Center for Integrative Medical Sciences, Yokohama, Japan

13 Department of Healthcare Administration, Nagoya University Graduate School of Medicine, Nagoya, Japan 
their sibling(s) had a history of GC compared with those with no family history (OR 3.35, $95 \%$ CI $0.75-14.96$ and OR 3.51, $95 \%$ CI 1.35-9.15 respectively).

Conclusions $M M P 9$ polymorphisms were associated with a multiple family history of GC. Screening for these genotypes together with familial background may help us to identify individuals at an increased risk of GC.

Keywords $M M P 9$ - Genetic polymorphism - Gastric cancer $\cdot$ Family history $\cdot$ Epidemiology

\section{Introduction}

Gastric cancer (GC) is one of the commonest malignancies worldwide, and the highest rate of GC is observed in eastern Asian countries, especially in Japan [1]. It is well known that having a first-degree relative with $\mathrm{GC}$ is a consistent risk factor for GC [2-4], especially when two or more relatives are affected [5, 6]. Familial aggregation of GC may be caused by shared environmental factors as well as common genetic backgrounds [7]. There are several reports showing the association between some genetic polymorphisms and GC or other cancer risks among individuals with a family history of cancers $[8,9]$.

GC expresses enhanced levels of matrix metalloproteinases (MMPs) and tissue inhibitors of metalloproteinases (TIMPs) [10-12]. MMPs degrade structural components of the extracellular matrix (ECM) and are thus closely associated with cancer invasion and metastasis [13]. Moreover, MMPs may have some roles in carcinogenesis and early cancer biology [14], and genetic variants of MMPs influence their expression and are associated with an increased susceptibility to several different types of cancer [15], including GC [16-18]. However, there are no data on the associations between these genetic variations and a familial background of GC.

Therefore, the present study was undertaken to investigate the associations of potentially functional polymorphisms in the MMP and TIMP genes with the risk of having a multiple family history of GC in middle-aged Japanese individuals.

\section{Subjects and methods}

\section{Study subjects}

The study subjects were participants in the Japan Multiinstitutional Collaborative Cohort (J-MICC) Study, a large cohort study designed to identify and evaluate gene-environment interactions in the context of lifestyle-related diseases. Individuals aged 35-69 years across ten regions of Japan voluntarily provided blood samples and recorded lifestyle data using questionnaires. The design of the J-MICC Study is described in more detail elsewhere [19]. For this cross-sectional study, 4514 subjects were selected from participants across ten regions of Japan between 2004 and 2008 [20]. Subjects were presumably healthy volunteers or health checkup examinees. Among those, subjects who were ineligible or were withdrawn from the study $(n=25)$, for whom a sufficient amount of DNA samples was lacking $(n=6)$, and who had a history of GC $(n=49)$ were excluded, resulting in 4434 subjects being included in the analyses. Written informed consent was obtained from all subjects. The study protocol was approved by the ethics committees at Nagoya University School of Medicine and the participating institutions.

\section{Classification according to the type of family history of GC}

Information on the first-degree family history of GC (parents and siblings) was collected by the questionnaire. Subjects who have two or more first-degree relatives with $\mathrm{GC}$ were categorized as having a multiple family history of $\mathrm{GC}$, and those with one or no first-degree relative with a history of GC were categorized as having a single or no family history of GC respectively.

The family history of GC was classified in detail according to the type of affected family member. The subjects with a single family history of GC were categorized into "one parent" or "one sibling" groups and the subjects with a multiple family history of GC were categorized into "one parent and sibling(s)" or "both parents" groups. Subjects with other categories (e.g., three siblings) were excluded from the analysis $(n=7)$, resulting in 4427 subjects being included in the analyses.

\section{Selection and genotyping of polymorphisms}

The MMP and TIMP genes evaluated in this study included $M M P 1$ (which encodes interstitial collagenase), MMP2 (which encodes gelatinase A), MMP3 (which encodes stromelysin 1), MMP9 (which encodes gelatinase B), TIMP2, and TIMP3, on the basis of prior publications [17]. We selected single nucleotide polymorphisms (SNPs) in the promoter regions of these genes and nonsynonymous SNPs with minor allele frequencies in the Japanese population of more than 0.100 , identified with use of the dbSNP (http://www.ncbi.nlm.nih.gov/projects/SNP/) and HapMap (http://hapmap.ncbi.nlm.nih.gov/) databases. The initially selected polymorphisms were further screened according to the biological evidence of a literature review [16-18, 21]. Using this evidence, we selected the following ten SNPs: MMP1-1607 1G/2G (rs1799750), MMP2 C-1306T 
(rs243865), MMP2 C-735T (rs2285053), MMP3-1612 5A/ 6A (rs3025058), MMP3 Glu45Lys (E45K, G/A, rs679620), MMP9 C-1562T (rs3918242), MMP9 Arg279Gln (R279Q, G836A, rs17576 or previously rs2664538), MMP9 Arg668Gln (R668Q, G2003A, rs17577 or previously rs2274756), TIMP2 G-418C (rs8179090), and TIMP3 T-1296C (rs9619311).

We extracted DNA from buffy coat fractions using of a BioRobot M48 workstation (Qiagen, Tokyo, Japan) or from whole blood using an automatic nucleic acid isolation system (NA-3000; KURABO, Osaka, Japan). We genotyped the SNPs using a multiplex PCR-based Invader assay (Third Wave Technologies, Madison, WI, USA) [22] at the Laboratory for Genotyping Development, Center for Genomic Medicine, RIKEN. The genotype call rates ranged from 99.75 to $99.98 \%$.

\section{Statistical analysis}

The characteristics of subjects were compared between those whose both parents had a history of GC and those with no family history of GC with use of Student's $t$ test, the $\chi^{2}$ test, or the Wilcoxon rank sum test as appropriate. The genotype distributions were tested for Hardy-Weinberg equilibrium by the $\chi^{2}$ test. Odds ratios (ORs) for the prevalence of subjects whose both parents had a history of GC were estimated by unconditional logistic regression analysis with $95 \%$ confidence intervals (CIs). ORs were adjusted for age, sex, and current smoking. Haplotype frequencies were estimated by the expectation- maximization algorithm. The population attributable fraction was calculated by the following formula: population attributable fraction $=\left[p_{1}\left(\mathrm{OR}_{1}-1\right)+p_{2}\left(\mathrm{OR}_{2}-1\right)\right] /\left[p_{1-}\right.$ $\left.\left(\mathrm{OR}_{1}-1\right)+p_{2}\left(\mathrm{OR}_{2}-1\right)+1\right]$, where $p_{1}$ is the proportion of minor homozygous genotype, $p_{2}$ is the proportion of heterozygous genotype, $\mathrm{OR}_{1}$ is the $\mathrm{OR}$ for the prevalence of a multiple family history of GC of minor homozygous genotype, and $\mathrm{OR}_{2}$ is the $\mathrm{OR}$ of heterozygous genotype [23]. All the $P$ values were two-sided, and all analyses were performed with STATA version 9 (StataCorp, College Station, TX, USA).

\section{Results}

The characteristics of the subjects are summarized in Table 1. Subjects with a multiple family history of GC accounted for $1.3 \%(59 / 4427)$ of the whole population, whereas $12.5 \%$ had a single family history of GC. The subjects whose both parents had a history of GC were older and the prevalence of females was greater, but the prevalence of current smokers or current drinkers was not different. The number of siblings was not statistically different between subjects whose both parents had a history of GC and those with no family history of GC.

All of the genotype frequencies were in Hardy-Weinberg equilibrium $(P>0.05)$. MMP9 279QQ was more frequently observed in subjects whose both parents had a history of GC compared with those with no family history of GC (30.4\% vs $11.6 \%$, OR 4.34, $95 \%$ CI 1.45-13.03

Table 1 Characteristics of subjects according to the type of family history of gastric cancer $(n=4427)$

\begin{tabular}{|c|c|c|c|c|c|c|}
\hline & \multicolumn{5}{|c|}{ Family history of gastric cancer } & \multirow[t]{3}{*}{$P^{\mathrm{a}}$} \\
\hline & \multirow{2}{*}{$\begin{array}{l}\text { Negative } \\
(n=3816)\end{array}$} & \multicolumn{2}{|l|}{ Single } & \multicolumn{2}{|l|}{ Multiple } & \\
\hline & & $\begin{array}{l}1 \text { sibling } \\
(n=104)\end{array}$ & $\begin{array}{l}1 \text { parent } \\
(n=448)\end{array}$ & $\begin{array}{l}1 \text { parent and } \\
\text { sibling(s) }(n=36)\end{array}$ & $\begin{array}{l}\text { Both parents } \\
(n=23)\end{array}$ & \\
\hline Age (years) & $55.5 \pm 9.0$ & $61.1 \pm 6.8$ & $56.1 \pm 8.1$ & $59.9 \pm 5.5$ & $60.6 \pm 7.0$ & 0.004 \\
\hline Male & $1775(46.5 \%)$ & $258(46.7 \%)$ & $258(46.7 \%)$ & $35(53.0 \%)$ & $7(30.4 \%)$ & 0.027 \\
\hline Body mass index $\left(\mathrm{kg} / \mathrm{m}^{2}\right)^{\mathrm{b}}$ & $23.4 \pm 3.3$ & $23.8 \pm 3.3$ & $23.5 \pm 3.3$ & $23.6 \pm 2.9$ & $24.1 \pm 3.5$ & 0.179 \\
\hline $\begin{array}{l}\text { Fasting plasma glucose } \\
(\mathrm{mg} / \mathrm{dl})^{\mathrm{c}}\end{array}$ & $99.8 \pm 21.9$ & $99.3 \pm 13.4$ & $99.2 \pm 19.6$ & $99.2 \pm 11.6$ & $94.9 \pm 8.1$ & 0.189 \\
\hline Hemoglobin A1c $(\%)^{\mathrm{d}}$ & $5.58 \pm 0.70$ & $5.62 \pm 0.52$ & $5.54 \pm 0.53$ & $5.59 \pm 0.42$ & $5.53 \pm 0.42$ & 0.403 \\
\hline Current smokers & $686(18.0 \%)$ & $84(15.2 \%)$ & $84(15.2 \%)$ & $10(15.2 \%)$ & $4(17.4 \%)$ & 0.942 \\
\hline Current drinkers & $2136(56.0 \%)$ & $303(54.9 \%)$ & $303(54.9 \%)$ & $41(62.1 \%)$ & $14(60.9 \%)$ & 0.637 \\
\hline Number of siblings & $2(1-4)$ & $4(3-6)$ & $2(2-4)$ & $4(3-5)$ & $3(2-4)$ & 0.488 \\
\hline
\end{tabular}

Data are the mean \pm standard deviation, the number and percentage (in parentheses), or the median and the interquartile range (in parentheses).

${ }^{a}$ By Student's $t$ test, the $\chi^{2}$ test, or the Wilcoxon rank-sum test for comparison between subjects whose both parents had a history of gastric cancer and those with no family history of gastric cancer

b $n=3375$

c $n=2366$

${ }^{\mathrm{d}} n=2697$ 
after adjustment for age, sex, and current smoking) (Table 2). The association was consistent when subjects who had no sibling $(n=165)$ were excluded (OR 5.10, $95 \%$ CI 1.61-16.18), and the association was consistent when the number of siblings was adjusted (OR 3.95, $95 \%$ CI 1.25-12.42). Population attributable fraction was calculated as $38.1 \%$.

The results of multiple logistic regression analysis including age, sex, smoking status, and genotype are shown in Table 3. Subjects whose both parents had a history of GC showed the highest frequency of having MMP9 279QQ genotype, and subjects for whom one parent and their sibling(s) had a history of GC (another type of multiple family history of GC) and subjects for whom one sibling (but no parent) had a history of GC showed a higher frequency of having the risk genotype, although these associations were not statistically significant. Subjects for whom one parent (but no siblings) had a history of GC showed no difference in the frequency of having the risk genotype compared with those with no family history of GC. Age was associated with having a family history of GC. Noncurrent smokers tended to have higher risk of having a family history of GC, although the association was not statistically significant.

Since the three SNPs in $M M P 9$ were in linkage disequilibrium $\left(D^{\prime}=0.992, r^{2}=0.102\right.$ between $\mathrm{C}-1562 \mathrm{~T}$ and $\mathrm{R} 279 \mathrm{Q}, \quad D^{\prime}=0.672, r^{2}=0.055$ between R279Q and $\mathrm{R} 668 \mathrm{Q}$, and $D^{\prime}=0.996, r^{2}=0.848$ between R668Q and C-1562T), haplotype analysis was conducted. Table 4 shows the frequency distribution of $M M P 9$ haplotypes according to the type of family history of GC. Almost all the alleles $(99.7 \%)$ were classified into four haplotypes, and the haplotypes $M M P 9-1562 \mathrm{C} / 279 \mathrm{Q} / 668 \mathrm{R}$ and $M M P 9$ $-1562 \mathrm{C} / 279 \mathrm{Q} / 668 \mathrm{Q}$ were more frequently observed in subjects whose both parents had a history of GC compared with those with no family history of GC (OR $2.60,95 \%$ CI 1.31-5.17 and OR 3.35, $95 \%$ CI $0.75-14.96$ after the adjustment respectively). Also, these haplotypes were more frequently observed in subjects for whom one parent and their sibling(s) had a history of GC compared with those with no family history of GC (OR $1.34,95 \%$ CI $0.80-2.25$ for C-Q-R and OR 3.51, $95 \%$ CI $1.35-9.15$ for C-Q-Q after the adjustment). The haplotype distribution was not different between subjects with a single family history of GC (one sibling or one parent) and those with no family history of GC.

\section{Discussion}

We found that MMP9 279QQ was more prevalent in subjects who have two or more first-degree relatives with GC compared with those with no family history of GC. To the best of our knowledge, this is the first large molecular epidemiologic study that has investigated the association of MMP9 polymorphisms with a family history of GC.

Having a first-degree relative with $\mathrm{GC}$ is a consistent risk factor for GC [2-4]. Moreover, having a multiple family history of GC is a stronger risk factor for GC compared with no or a single family history of GC (ORs 5.7 and 1.7 in subjects with a multiple and a single family history of GC respectively) [5, 6]. Our results may be consistent with those of previous studies indicting that GC risk was high in subjects with a multiple family history of $\mathrm{GC}$, and among them the risk was especially high when both parents were affected [5, 6]. Thus, a detailed family history assessment of cancer, including the number of affected first-degree relatives, is needed before genetic risk assessment [24].

Familial aggregation of GC may be caused by shared environmental factors as well as common genetic backgrounds [7]. Families that share similar surroundings will be exposed to the same risk factors, such as infection with Helicobacter pylori and dietary factors. In addition, the risk may also be influenced by genetic polymorphisms [7]. It is well known that the mutation of the E-cadherin gene $(\mathrm{CDHI})$ is causal in hereditary diffuse gastric cancer cases [7], and some other polymorphisms are reported to be associated with the risk of GC [25].

MMPs are frequently overexpressed in various human cancers, including GC $[10,11]$. Historically, MMPs were considered to play important roles in cancer invasion and metastasis [13]. However, MMPs are also involved in early carcinogenesis via turnover and processing of receptors and other proteinases [14]. MMPs mediate ECM and basementmembrane degradation during the early stages of carcinogenesis [15]. Among them, MMP-9 has been proposed as a novel biomarker of cancer [12]. MMP-9 degrades the principal components of the ECM, collagen types IV and V and gelatin [26]. Experimental studies have shown that MMP9-null mice develop fewer cancers than wild-type mice in a carcinogenic model, showing the importance of the inflammatory cells in carcinogenesis [27]. In addition, MMP-9 is an index of inflammation-related processes occurring in the malignant phase of carcinogenesis [28].

MMP gene polymorphisms may alter the expression and activity of the enzyme, increasing ECM degradation, leading to an increased susceptibility to several different types of cancer [15, 29], including GC [16-18]. MMP9 R279Q polymorphism leads to an amino acid exchange (arginine to glycine) in the fibronectin type II domain of the catalytic domain that plays an important role in substrate binding [30, 31], suggesting that MMP-9 activity levels may be higher in subjects with the 279QQ genotype [30]. The T allele of MMP9 -1562 is associated with elevated MMP-9 plasma concentration [32] in accordance with the 
Table 2 Matrix metalloproteinase and tissue inhibitor of metalloproteinases genotypes according to the type of family history of gastric cancer $(n=4427)$

\begin{tabular}{|c|c|c|c|c|c|c|}
\hline \multirow[t]{3}{*}{ Genotype } & \multicolumn{5}{|c|}{ Family history of gastric cancer } & \multirow[t]{3}{*}{ Adjusted $\mathrm{OR}^{\mathrm{a}}$} \\
\hline & \multirow{2}{*}{$\begin{array}{l}\text { Negative } \\
(n=3816)\end{array}$} & \multicolumn{2}{|l|}{ Single } & \multicolumn{2}{|l|}{ Multiple } & \\
\hline & & $\begin{array}{l}1 \text { sibling } \\
(n=104)\end{array}$ & $\begin{array}{l}1 \text { parent } \\
(n=448)\end{array}$ & $\begin{array}{l}1 \text { parent and } \\
\text { sibling(s) }(n=36)\end{array}$ & $\begin{array}{l}\text { Both parents } \\
(n=23)\end{array}$ & \\
\hline \multicolumn{7}{|c|}{$M M P 1-16071 \mathrm{G} / 2 \mathrm{G}(\mathrm{rs} 1799750)$} \\
\hline $2 \mathrm{G} 2 \mathrm{G}$ & $1748(45.9 \%)$ & $43(41.4 \%)$ & $194(43.3 \%)$ & $17(47.2 \%)$ & $12(52.2 \%)$ & 1.00 \\
\hline $2 \mathrm{G} 1 \mathrm{G}$ & $1677(44.0 \%)$ & $54(51.9 \%)$ & $206(46.0 \%)$ & $18(50.0 \%)$ & $9(39.1 \%)$ & $\begin{array}{l}0.80 \\
\quad(0.34-1.91)\end{array}$ \\
\hline $1 \mathrm{G} 1 \mathrm{G}$ & $385(10.1 \%)$ & $7(6.7 \%)$ & $48(10.7 \%)$ & $1(2.8 \%)$ & $2(8.7 \%)$ & $\begin{array}{l}0.72 \\
\quad(0.16-3.25)\end{array}$ \\
\hline \multicolumn{7}{|c|}{ MMP2 C-1306T (rs243865) } \\
\hline $\mathrm{C} \mathrm{C}$ & $3303(86.7 \%)$ & $89(85.6 \%)$ & $377(84.2 \%)$ & $32(88.9 \%)$ & $21(91.3 \%)$ & 1.00 \\
\hline $\mathrm{C} \mathrm{T}$ & $488(12.8 \%)$ & $15(14.4 \%)$ & $70(15.6 \%)$ & $4(11.1 \%)$ & $2(8.7 \%)$ & $\begin{array}{l}0.64 \\
\quad(0.15-2.76)\end{array}$ \\
\hline $\mathrm{T} \mathrm{T}$ & $20(0.5 \%)$ & $0(0 \%)$ & $1(0.2 \%)$ & $0(0 \%)$ & $0(0.0 \%)$ & - \\
\hline \multicolumn{7}{|c|}{ MMP2 C-735T (rs2235053) } \\
\hline $\mathrm{C} \mathrm{C}$ & $2022(53.0 \%)$ & $55(52.9 \%)$ & $230(51.3 \%)$ & $19(52.8 \%)$ & $13(56.5 \%)$ & 1.00 \\
\hline $\mathrm{C} \mathrm{T}$ & $1492(39.1 \%)$ & $44(42.3 \%)$ & $181(40.4 \%)$ & $12(33.3 \%)$ & $8(34.8 \%)$ & $\begin{array}{l}0.82 \\
\quad(0.34-1.98)\end{array}$ \\
\hline $\mathrm{T} \mathrm{T}$ & $298(7.8 \%)$ & $5(4.8 \%)$ & $37(8.3 \%)$ & $5(13.9 \%)$ & $2(8.7 \%)$ & $\begin{array}{l}1.01 \\
(0.723-4.53)\end{array}$ \\
\hline \multicolumn{7}{|c|}{ MMP3-1612 5A/6A (rs3025058) } \\
\hline $6 \mathrm{~A} 6 \mathrm{~A}$ & $2800(73.4 \%)$ & $81(77.9 \%)$ & $324(72.5 \%)$ & $29(80.6 \%)$ & $16(69.6 \%)$ & 1.00 \\
\hline $6 \mathrm{~A} 5 \mathrm{~A}$ & $943(24.7 \%)$ & $21(20.2 \%)$ & $113(25.3 \%)$ & $7(19.4 \%)$ & $6(26.1 \%)$ & $\begin{array}{l}1.11 \\
\quad(0.43-2.86)\end{array}$ \\
\hline $5 \mathrm{~A} 5 \mathrm{~A}$ & $71(1.9 \%)$ & $2(1.9 \%)$ & $10(2.2 \%)$ & $0(0 \%)$ & $1(4.4 \%)$ & $\begin{array}{l}2.85 \\
\quad(0.37-22.08)\end{array}$ \\
\hline \multicolumn{7}{|c|}{ MMP3 E45K (Glu45Lys, rs679620) } \\
\hline E E & $1866(48.9 \%)$ & $47(45.2 \%)$ & $200(44.7 \%)$ & $19(52.8 \%)$ & $12(52.2 \%)$ & 1.00 \\
\hline E K & $1602(42.0 \%)$ & $47(45.2 \%)$ & $192(43.0 \%)$ & $16(44.4 \%)$ & $9(39.1 \%)$ & $\begin{array}{l}0.91 \\
\quad(0.38-2.16)\end{array}$ \\
\hline K K & $346(9.1 \%)$ & $10(9.6 \%)$ & $55(12.3 \%)$ & $1(2.8 \%)$ & $2(8.7 \%)$ & $\begin{array}{l}0.85 \\
\quad(0.19-3.81)\end{array}$ \\
\hline \multicolumn{7}{|c|}{ MMP9 C-1562T (rs3918242) } \\
\hline $\mathrm{C} \mathrm{C}$ & $2651(69.7 \%)$ & $73(70.2 \%)$ & $313(69.9 \%)$ & $27(75.0 \%)$ & $15(65.2 \%)$ & 1.00 \\
\hline $\mathrm{C} \mathrm{T}$ & $1040(27.3 \%)$ & $28(26.9 \%)$ & $122(27.2 \%)$ & $9(25.0 \%)$ & $7(30.4 \%)$ & $\begin{array}{l}1.27 \\
\quad(0.52-3.14)\end{array}$ \\
\hline $\mathrm{T} \mathrm{T}$ & $114(3.0 \%)$ & $3(2.9 \%)$ & $13(2.9 \%)$ & $0(0 \%)$ & $1(4.4 \%)$ & $\begin{array}{l}1.59 \\
(0.21-12.19)\end{array}$ \\
\hline \multicolumn{7}{|c|}{ MMP9 R279Q (Arg279Gln, rs17576) } \\
\hline R R & $1638(43.1 \%)$ & $47(45.2 \%)$ & $210(46.9 \%)$ & $10(27.8 \%)$ & $6(26.1 \%)$ & \\
\hline R Q & $1725(45.3 \%)$ & $36(34.6 \%)$ & $191(42.6 \%)$ & $20(55.6 \%)$ & $10(43.5 \%)$ & $\begin{array}{l}1.49 \\
\quad(0.54-4.12)\end{array}$ \\
\hline Q Q & $442(11.6 \%)$ & $21(20.2 \%)$ & $47(10.5 \%)$ & $6(16.7 \%)$ & $7(30.4 \%)$ & $\begin{array}{l}4.34 \\
\quad(1.45-13.03)\end{array}$ \\
\hline \multicolumn{7}{|c|}{ MMP9 R668Q (Arg668Gln, rs17577) } \\
\hline R R & $2511(65.8 \%)$ & $71(68.3 \%)$ & $297(66.3 \%)$ & $23(63.9 \%)$ & $13(56.5 \%)$ & 1.00 \\
\hline R Q & $1165(30.6 \%)$ & $29(27.9 \%)$ & $134(29.9 \%)$ & $12(33.3 \%)$ & $9(39.1 \%)$ & $\begin{array}{l}1.57 \\
\quad(0.67-3.70)\end{array}$ \\
\hline Q Q & $138(3.6)$ & $4(3.9 \%)$ & $17(3.8 \%)$ & $1(2.8 \%)$ & $1(4.4 \%)$ & $\begin{array}{l}1.41 \\
\quad(0.18-10.87)\end{array}$ \\
\hline
\end{tabular}


Table 2 continued

\begin{tabular}{|c|c|c|c|c|c|c|}
\hline \multirow[t]{3}{*}{ Genotype } & \multicolumn{5}{|c|}{ Family history of gastric cancer } & \multirow[t]{3}{*}{ Adjusted $\mathrm{OR}^{\mathrm{a}}$} \\
\hline & \multirow{2}{*}{$\begin{array}{l}\text { Negative } \\
(n=3816)\end{array}$} & \multicolumn{2}{|l|}{ Single } & \multicolumn{2}{|l|}{ Multiple } & \\
\hline & & $\begin{array}{l}1 \text { sibling } \\
(n=104)\end{array}$ & $\begin{array}{l}1 \text { parent } \\
(n=448)\end{array}$ & $\begin{array}{l}1 \text { parent and } \\
\text { sibling }(\mathrm{s})(n=36)\end{array}$ & $\begin{array}{l}\text { Both parents } \\
(n=23)\end{array}$ & \\
\hline \multicolumn{7}{|c|}{ TIMP2 G-418C (rs8179090) } \\
\hline G G & $2531(66.3 \%)$ & $68(65.4 \%)$ & $309(69.0 \%)$ & $20(55.6 \%)$ & $18(78.3 \%)$ & 1.00 \\
\hline $\mathrm{G} \mathrm{C}$ & $1154(30.3 \%)$ & $32(30.8 \%)$ & $124(27.7 \%)$ & $15(41.7 \%)$ & $5(21.7 \%)$ & $\begin{array}{l}0.89 \\
\quad(0.33-2.40)\end{array}$ \\
\hline $\mathrm{C} \mathrm{C}$ & $130(3.4)$ & $4(3.9 \%)$ & $15(3.4 \%)$ & $1(2.8 \%)$ & $0(0 \%)$ & - \\
\hline \multicolumn{7}{|c|}{ TIMP3 T-1296C (rs9619311) } \\
\hline $\mathrm{T} \mathrm{T}$ & $3087(80.9 \%)$ & $79(76.0 \%)$ & $376(83.9 \%)$ & $29(80.6 \%)$ & $22(95.7 \%)$ & 1.00 \\
\hline $\mathrm{T} \mathrm{C}$ & $695(18.2 \%)$ & $24(23.1 \%)$ & $68(15.2 \%)$ & $7(19.4 \%)$ & $1(4.4 \%)$ & $\begin{array}{l}0.20 \\
\quad(0.03-1.52)\end{array}$ \\
\hline $\mathrm{C} \mathrm{C}$ & $32(0.8 \%)$ & $1(1.0 \%)$ & $4(0.9 \%)$ & $0(0 \%)$ & $0(0 \%)$ & - \\
\hline
\end{tabular}

Italic style represents statistically significant ORs after adjustments

$O R$ odds ratio

a Subjects whose both parents had a history of gastric cancer were compared with those with no family history of gastric cancer. Adjustment was made for age, sex, and current smoking. The $95 \%$ confidence interval is given in parentheses

Table 3 Odds ratios from multiple logistic regression analysis for having a family history of gastric cancer

\begin{tabular}{|c|c|c|c|c|c|}
\hline & \multicolumn{5}{|c|}{ Family history of gastric cancer } \\
\hline & \multirow[t]{2}{*}{ Negative $(n=3,816)$} & \multicolumn{2}{|l|}{ Single } & \multicolumn{2}{|l|}{ Multiple } \\
\hline & & 1 sibling $(n=104)$ & 1 parent $(n=448)$ & 1 parent and sibling(s) $(n=36)$ & Both parents $(n=23)$ \\
\hline MMP9 279QQ & 1 (reference) & $1.65(0.97-2.80)$ & $0.83(0.59-1.16)$ & $2.26(0.81-6.27)$ & $4.34(1.45-13.03)$ \\
\hline Age (per year) & 1 (reference) & $1.08(1.05-1.12)$ & $1.01(0.99-1.03)$ & $1.09(1.02-1.18)$ & $1.07(0.99-1.15)$ \\
\hline Male & 1 (reference) & $1.18(0.71-1.96)$ & $1.13(0.86-1.48)$ & $0.88(0.31-2.49)$ & $1.26(0.28-6.26)$ \\
\hline Current smoker & 1 (reference) & $0.63(0.29-1.36)$ & $0.79(0.54-1.15)$ & $0.76(0.16-3.59)$ & - \\
\hline
\end{tabular}

The $95 \%$ confidence interval is given in parentheses

Italic style represents statistically significant ORs after adjustments

increased promoter activity of the $-1562 \mathrm{~T}$ allele [33]. As a result, $M M P 9 \mathrm{C}-1562 \mathrm{~T}$ is associated with susceptibility to GC [34]. On the other hand, MMP9 R668Q is located in the hemopexin-like domain, which is necessary for the collagenase activity of MMP-9 [35], and is associated with survival in lung cancer [36] and melanoma [37].

Our results are consistent with those of previous studies; the MMP9 279QQ genotype or a $\mathrm{Q}$ allele was associated with occurrence of GC without lymph node metastasis [38], survival in lung cancer [36 prostate cancer [39], intransit metastasis in melanoma [37], and higher grade of renal cell carcinoma [40]. There are controversial findings, however, that MMP9 279QQ is negatively associated with the risk of lymph node metastasis of the diffuse type of GC [38], which might be caused by the difference between the type of GC (diffuse and intestinal) [38]. Although we do not have information of the GC type in the family members, intestinal type is more frequent than diffuse type in
Japan [41]. To date, no study has focused on the association between $M M P 9 \mathrm{R} 279 \mathrm{Q}$ polymorphism and a family history of GC, and the exact biological mechanism in relation to this association remains to be revealed.

We showed that the two haplotypes containing the MMP9 279Q allele were more frequently observed in subjects with a multiple family history of GC, and the haplotype with both the MMP9 279Q allele and the MMP9 668Q allele showed the highest frequency among subjects with a multiple family history of GC. Thus, MMP $279 \mathrm{Q}$ might be the most important allele and, moreover, $M M P 9$ 668Q might be a useful allele for stratifying the strength of the risk of having a multiple family history of GC. Further research is needed to prove this hypothesis.

Several limitations should be mentioned. First, we could not differentiate the diffuse type of GC from the intestinal type, which affected the relatives. Since the familial aggregation is different between the intestinal type and the 
Table 4 Comparison of the estimated haplotype frequencies of the MMP9 gene (C-1562T-R279Q-R668Q) according to the type of family history of gastric cancer $(n=4404)$

\begin{tabular}{|c|c|c|c|c|c|c|c|}
\hline \multirow[t]{4}{*}{ Haplotype } & \multicolumn{7}{|c|}{ Family history of gastric cancer } \\
\hline & \multirow{3}{*}{$\begin{array}{l}\text { Negative } \\
(n=3793) \\
n\end{array}$} & \multicolumn{2}{|l|}{ Single } & \multicolumn{4}{|l|}{ Multiple } \\
\hline & & \multirow{2}{*}{$\begin{array}{l}1 \text { sibling } \\
(n=104) \\
n\end{array}$} & \multirow{2}{*}{$\begin{array}{l}1 \text { parent } \\
(n=448) \\
n\end{array}$} & \multicolumn{2}{|c|}{$\begin{array}{l}1 \text { parent and } \\
\operatorname{sibling}(\mathrm{s})(n=36)\end{array}$} & \multicolumn{2}{|c|}{ Both parents $(n=23)$} \\
\hline & & & & $n$ & $\mathrm{OR}^{\mathrm{a}}$ & $n$ & $\mathrm{OR}^{\mathrm{a}}$ \\
\hline C-R-R & $3724(49.1 \%)$ & $95(45.7 \%)$ & $462(51.5 \%)$ & $31(43.1 \%)$ & 1 (reference) & $13(28.3 \%)$ & 1 (reference) \\
\hline T-R-Q & $1256(16.6 \%)$ & $34(16.3 \%)$ & $148(16.5 \%)$ & $9(12.5 \%)$ & $\begin{array}{l}0.86 \\
\quad(0.41-1.81)\end{array}$ & $9(19.6 \%)$ & $2.05(0.88-4.81)$ \\
\hline C-Q-R & $2425(32.0 \%)$ & $76(36.5 \%)$ & $266(29.7 \%)$ & $27(37.5 \%)$ & $\begin{array}{l}1.34 \\
(0.80-2.25)\end{array}$ & $22(47.8 \%)$ & $2.60(1.31-5.17)$ \\
\hline C-Q-Q & $171(2.3 \%)$ & $2(1.0 \%)$ & $19(2.1 \%)$ & $5(6.9 \%)$ & $\begin{array}{l}3.51 \\
\quad(1.35-9.15)\end{array}$ & $2(4.3 \%)$ & $\begin{array}{l}3.35 \\
(0.75-14.96)\end{array}$ \\
\hline
\end{tabular}

Subjects with complete data for three genotypes were used

Italic style represents statistically significant ORs after adjustments

$O R$ odds ratio

a The $95 \%$ confidence is given in parentheses

diffuse type [4], further detailed study is needed. Second, there are no data on infection with $H$. pylori, a strong risk factor for GC with familial clustering [42]. However, as there is no report that MMP9 R279Q polymorphism has some influence on susceptibility to $H$. pylori infection or the progression to atrophic gastritis due $H$. pylori infection, the lack of data on $H$. pylori infection may not influence the result in this analysis. Third, as this is an exploratory study to seek an association between MMP and TIMP genotypes and subjects with a family history of GC, further study to evaluate the reproducibility is needed, and whether subjects having the genetic risk genotypes are more susceptible to GC should be elucidated by longitudinal studies.

In conclusion, we have demonstrated that potentially functional polymorphisms of $M M P 9$ are associated with a multiple family history of GC in a large Japanese population. Screening for these genotypes together with information of the familial background may help us identify individuals at an increased risk of GC.

Acknowledgments This study was supported in part by Grants-inAid for Scientific Research on Priority Areas of Cancer (no. 17015018) and Innovative Areas (No. 221S0001) from the Japanese Ministry of Education, Culture, Sports, Science and Technology. The authors thank Kyota Ashikawa, Tomomi Aoi, and other members of the Laboratory for Genotyping Development, Center for Genomic Medicine, RIKEN, for support with genotyping. The authors also thank Yoko Mitsuda, Keiko Shibata, and Etsuko Kimura from the Department of Preventative Medicine, Nagoya University Graduate School of Medicine, for technical assistance.

\section{Compliance with ethical standards}

Conflict of interest None of the authors have a conflict of interest that could potentially influence the research described.
Human rights statement All procedures followed were in accordance with the ethical standards of the responsible committee on human experimentation (institutional and national) and with the Helsinki Declaration of 1964 and later versions.

Informed consent Informed consent was obtained from all patients for their being included in the study.

\section{References}

1. Roder DM. The epidemiology of gastric cancer. Gastric Cancer. 2002;5(Suppl 1):5-11.

2. Yaghoobi M, Bijarchi R, Narod SA. Family history and the risk of gastric cancer. Br J Cancer. 2010;102:237-42.

3. Foschi R, Lucenteforte E, Bosetti C, Bertuccio P, Tavani A, La Vecchia C, et al. Family history of cancer and stomach cancer risk. Int J Cancer. 2008;123:1429-32.

4. Bernini M, Barbi S, Roviello F, Scarpa A, Moore P, Pedrazzani $\mathrm{C}$, et al. Family history of gastric cancer: a correlation between epidemiologic findings and clinical data. Gastric Cancer. 2006;9:9-13.

5. Yatsuya H, Toyoshima H, Mizoue T, Kondo T, Tamakoshi K, Hori Y, et al. Family history and the risk of stomach cancer death in Japan: differences by age and gender. Int $\mathbf{J}$ Cancer. 2002;97:688-94.

6. Palli D, Galli M, Caporaso NE, Cipriani F, Decarli A, Saieva C, et al. Family history and risk of stomach cancer in Italy. Cancer Epidemiol Biomarkers Prev. 1994;3:15-8.

7. Barber M, Fitzgerald RC, Caldas C. Familial gastric canceraetiology and pathogenesis. Best Pract Res Clin Gastroenterol. 2006;20:721-34.

8. Bhat GA, Shah IA, Rafiq R, Nabi S, Iqbal B, Lone MM, et al. Family history of cancer and the risk of squamous cell carcinoma of oesophagus: a case-control study in Kashmir, India. Br J Cancer. 2015;113:524-32.

9. Ghosh A, Hartge P, Purdue MP, Chanock SJ, Amundadottir L, Wang Z, et al. Assessing disease risk in genome-wide association studies using family history. Epidemiology. 2012;23:616-22. 
10. Nomura H, Sato H, Seiki M, Mai M, Okada Y. Expression of membrane-type matrix metalloproteinase in human gastric carcinomas. Cancer Res. 1995;55:3263-6.

11. Chen SZ, Yao HQ, Zhu SZ, Li QY, Guo GH, Yu J. Expression levels of matrix metalloproteinase-9 in human gastric carcinoma. Oncol Lett. 2015;9:915-9.

12. Roy R, Yang J, Moses MA. Matrix metalloproteinases as novel biomarkers and potential therapeutic targets in human cancer. J Clin Oncol. 2009;27:5287-97.

13. Parsons SL, Watson SA, Brown PD, Collins HM, Steele RJ. Matrix metalloproteinases. Br J Surg. 1997;84:160-6.

14. Egeblad M, Werb Z. New functions for the matrix metalloproteinases in cancer progression. Nat Rev Cancer. 2002;2:161-74.

15. Overall CM, López-Otín C. Strategies for MMP inhibition in cancer: innovations for the post-trial era. Nat Rev Cancer. 2002;2:657-72.

16. Kubben FJ, Sier CF, Meijer MJ, van den Berg M, van der Reijden JJ, Griffioen G, et al. Clinical impact of MMP and TIMP gene polymorphisms in gastric cancer. Br J Cancer. 2006;95:744-51.

17. Yeh YC, Sheu BS. Matrix metalloproteinases and their inhibitors in the gastrointestinal cancers: current knowledge and clinical potential. Metalloproteinases Med. 2014;1:3-13.

18. Yang TF, Guo L, Wang Q. Meta-analysis of associations between four polymorphisms in the matrix metalloproteinases gene and gastric cancer risk. Asian Pac J Cancer Prev. 2014;15:1263-7.

19. Hamajima N, J-MICC Study Group. The Japan Multi-Institutional Collaborative Cohort Study (J-MICC Study) to detect gene-environment interactions for cancer. Asian Pac J Cancer Prev. 2007;8:317-23.

20. Wakai K, Hamajima N, Okada R, Naito M, Morita E, Hishida A, et al. Profile of participants and genotype distributions of 108 polymorphisms in a cross-sectional study of associations of genotypes with lifestyle and clinical factors: a Project in the Japan Multi-institutional Collaborative Cohort (J-MICC) Study. J Epidemiol. 2011;21:223-35.

21. Okada R, Kawai S, Naito M, Hishida A, Hamajima N, Shinchi K, et al. Matrix metalloproteinase-9 gene polymorphisms and chronic kidney disease. Am J Nephrol. 2012;36:444-50.

22. Ohnishi Y, Tanaka T, Ozaki K, Yamada R, Suzuki H, Nakamura Y. A high-throughput SNP typing system for genome-wide association studies. J Hum Genet. 2001;46:471-7.

23. Katz MH. Study design and statistical analysis: a practical guide for clinicians. 1st ed. Cambridge: Cambridge University Press; 2006. p. 168-9.

24. Brennan P, Claber O, Brennan T. Cancer family history triage: a key step in the decision to offer screening and genetic testing. Fam Cancer. 2013;12:497-502.

25. González CA, Sala N, Capellá G. Genetic susceptibility and gastric cancer risk. Int J Cancer. 2002;100:249-60.

26. Westermarck J, Kähäri VM. Regulation of matrix metalloproteinase expression in tumor invasion. FASEB J. 1999;13:781-92.

27. Coussens LM, Tinkle CL, Hanahan D, Werb Z. MMP-9 supplied by bone marrow-derived cells contributes to skin carcinogenesis. Cell. 2000;103:481-90.
28. Biasi F, Guina T, Maina M, Nano M, Falcone A, Aroasio E, et al. Progressive increase of matrix metalloprotease- 9 and interleukin8 serum levels during carcinogenic process in human colorectal tract. PLoS One. 2012;7:e41839.

29. Li H, Liang X, Qin X, Cai S, Yu S. Association of matrix metalloproteinase family gene polymorphisms with lung cancer risk: logistic regression and generalized odds of published data. Sci Rep. 2015;5:10056.

30. Shipley JM, Doyle GA, Fliszar CJ, Ye QZ, Johnson LL, Shapiro $\mathrm{SD}$, et al. The structural basis for the elastolytic activity of the 92-kDa and 72-kDa gelatinases. Role of the fibronectin type IIlike repeats. J Biol Chem. 1996;271:4335-41.

31. Zhang B, Henney A, Eriksson P, Hamsten A, Watkins H, Ye S. Genetic variation at the matrix metalloproteinase-9 locus on chromosome 20q12.2-13.1. Hum Genet. 1999;105:418-23.

32. Blankenberg S, Rupprecht HJ, Poirier O, Bickel C, Smieja M, Hafner G, et al. Plasma concentrations and genetic variation of matrix metalloproteinase 9 and prognosis of patients with cardiovascular disease. Circulation. 2003;107:1579-85.

33. Zhang B, Ye S, Herrmann SM, Eriksson P, de Maat M, Evans A, et al. Functional polymorphism in the regulatory region of gelatinase B gene in relation to severity of coronary atherosclerosis. Circulation. 1999;99:1788-94.

34. Krishnaveni D, Bhayal AC, Sri Manjari K, Vidyasagar A, Uma Devi M, Ramanna M, et al. MMP 9 gene promoter polymorphism in gastric cancer. Indian J Clin Biochem. 2012;27:259-64.

35. Murphy G, Knäuper V. Relating matrix metalloproteinase structure to function: why the "hemopexin" domain? Matrix Biol. 1997;15:511-8.

36. Jin G, Miao R, Hu Z, Xu L, Huang X, Chen Y, et al. Putative functional polymorphisms of MMP9 predict survival of NSCLC in a Chinese population. Int J Cancer. 2009;124:2172-8.

37. Cotignola J, Reva B, Mitra N, Ishill N, Chuai S, Patel A, et al. Matrix metalloproteinase-9 (MMP-9) polymorphisms in patients with cutaneous malignant melanoma. BMC Med Genet. 2007;8:10.

38. Tang Y, Zhu J, Chen L, Chen L, Zhang S, Lin J. Associations of matrix metalloproteinase- 9 protein polymorphisms with lymph node metastasis but not invasion of gastric cancer. Clin Cancer Res. 2008;14:2870-7.

39. Dos Reis ST, Villanova FE, De Andrade PM, Pontes J, Silva IA, Canavez FC, et al. Polymorphisms of the matrix metalloproteinases associated with prostate cancer. Mol Med Rep. 2008;1:517-20.

40. Awakura Y, Ito N, Nakamura E, Takahashi T, Kotani H, Mikami Y, et al. Matrix metalloproteinase-9 polymorphisms and renal cell carcinoma in a Japanese population. Cancer Lett. 2006;241:59-63.

41. Kaneko S, Yoshimura T. Time trend analysis of gastric cancer incidence in Japan by histological types, 1975-1989. Br J Cancer. 2001;84:400-5.

42. Brenner H, Arndt V, Stürmer T, Stegmaier C, Ziegler H, Dhom G. Individual and joint contribution of family history and Helicobacter pylori infection to the risk of gastric carcinoma. Cancer. 2000;88:274-9. 